\title{
Short-sighted evolution of virulence in parasitic honeybee workers (Apis mellifera capensis Esch.)
}

\author{
Robin F. A. Moritz ${ }^{1,2}$, Christian W. W. Pirk ${ }^{2}$, H. Randall Hepburn ${ }^{3,4}$ and \\ Peter Neumann ${ }^{3,4,5}$
}

(1) Institut für Biologie, Molekulare Ökologie, Martin-Luther-Universität HalleWittenberg, Hoher Weg 4, 06099 Halle (Saale), Germany

(2) Department of Zoology and Entomology, University of Pretoria, 0002 Pretoria, South Africa

(3) Department of Zoology and Entomology, Rhodes University, 6140 Grahamstown, South Africa

(4) Eastern Bee Research Institute, Yunnan Agricultural University, Heilongtan, Kunming, Yunnan Province, China

(5) Swiss Bee Research Centre, Agroscope Liebefeld-Posieux Research Station ALP, 3033 Bern, Switzerland

\section{Robin F. A. Moritz}

Email: r.moritz@zoologie.uni-halle.de

\section{Abstract}

The short-sighted selection hypothesis for parasite virulence predicts that winners of within-host competition are poorer at transmission to new hosts. Social parasitism by self-replicating, female-producing workers occurs in the Cape honeybee Apis mellifera capensis, and colonies of other honeybee subspecies are susceptible hosts. We found high within-host virulence but low transmission rates in a clone of social parasitic $A . m$. capensis workers invading the neighbouring subspecies $A$. $m$. scutellata. In contrast, parasitic workers from the endemic range of $A$. $m$. capensis showed low within-host virulence but high transmission rates. This suggests a short-sighted selection scenario for the host-parasite co-evolution in the invasive range of the Cape honeybee, probably facilitated by beekeeping-assisted parasite transmission in apiaries.

\section{Introduction}

Social parasitism is widespread in the social insects in which usually mated females seek colonies of a host species and start reproducing (interspecific social parasitism); however, social parasitism may also occur within a single species (intraspecific social parasitism, 
Schmid-Hempel 1998). It has long been known (Onions 1912) that Cape honeybee, Apis mellifera capensis, workers are facultative social parasites and that colonies of other subspecies are susceptible hosts (Allsopp 1993). Indeed, laying Cape honeybee workers parthenogenetically produce female clonal offspring (Moritz and Haberl 1994) and are predisposed for social parasitism (Neumann and Moritz 2002). After successful transmission, social parasitic $A$. $m$. capensis workers initiate oviposition despite the presence of the host queen (Neumann et al. 2001; Neumann and Hepburn 2002). Although worker-laid eggs are usually removed by other workers in queenright colonies (worker policing, Ratnieks and Visscher 1989), social parasitic Cape honeybee workers can evade this host defence mechanism (Moritz et al. 1999; Martin et al. 2002; Neumann and Moritz 2002; Neumann et al. 2003). The hatched larvae of the parasitic workers are then preferentially fed by the host workers (Beekman et al. 2000), and new parasitic workers are reared by the host colony. Eventually, the colony is composed of many parasitic workers, which do not participate in brood rearing and other hive tasks (Hillesheim et al. 1989). Then, the colony shows all symptoms of the dwindling colony syndrome and finally dies (Allsopp 1992).

Migratory beekeepers repeatedly moved large numbers of $A m$ capensis colonies (200 colonies) into the range of the neighbouring subspecies $A m$ scutellata in the Highveld of South Africa (Allsopp 1995). As a consequence, parasitic workers spread widely and infested 100,000 of host colonies every year (Allsopp and Crewe 1993), resulting in the "capensis" calamity for South African apiculture. The dramatic impact suggested that these invasive parasitic workers are highly virulent. Recent DNA microsatellite analyses showed that the invasive $A m$ capensis population constitutes a single clonal lineage and that all parasitic workers are offspring of a single highly virulent parasitic worker (Kryger 2001; Neumann and Moritz 2002; Baudry et al. 2004; Härtel et al. 2006a, b).

Selection for virulence has been explained by at least three different evolutionary routes (Levin 1996):

1. Direct selection: resulting in a positive relation between virulence and transmission

2. Coincidental evolution: resulting in high virulence due to selection at some other character which is linked to the virulence

3. Short-sighted within-host evolution: selecting the most virulent parasite within the host but reducing the rate at which the parasite is transmitted between hosts

Although short-sighted evolution has been proposed to occur in fast-evolving microparasites, e.g. viruses (Levin and Bull 1994), the capensis calamity may nevertheless also set conditions to allow for strong within-host selection and, hence, for short-sighted selection for parasite virulence. Within-host selection is based on the superior propagation of the most virulent parasitic type, which eventually will outcompete all other less virulent types in the host. Genetic variance in virulence of microparasites will quickly build up after infection because they typically have extremely short generation times, large population sizes and high mutation rates due to lacking 
DNA repair mechanisms. Selection can then act on this variation to favour those lineages that replicate faster before horizontal transmission to a new host occurs, which can result in a trade-off between virulence and transmission (Bull 1994). At first (short) sight, this scenario seems impossible in long-lived eucaryotes such as parasitic worker bees, which have the same generation time as the host and probably even longer than the duration of infection itself. Hence, there is clearly no potential for genetic variability to arise through mutation during the infection of a host colony as a basis for within-colony selection to work. However, multiple infections of parasitic workers with different genotypes can also cause within-host variation and form a basis for within-host selection. Given that over $200 \mathrm{~A}$. m. capensis colonies were transported, with about 20,000 workers each (Allsopp and Crewe 1993), the actual number of individual worker genotypes transported may well have exceeded four million workers per year. This results in a huge genetic variance for virulence, which is an essential prerequisite to allow for within-host colony selection. Because parasitic workers reproduce parthenogenetically with almost no recombination during meiosis (Moritz and Haberl 1994; Baudry et al. 2004), within-host selection can select for specific virulent genotypes, which are kept intact as clonal lineages that are not distorted during meiosis and sexual recombination.

We here study whether short-sighted evolution results in a trade-off for virulence and transmission in social parasitic workers. We test this by comparing survival of workerlaid eggs (as a measure of virulence) and the transmission capacity of Cape honeybee workers from a population in the natural distribution area of the Cape honeybee, with the parasitic population that caused the capensis calamity in South Africa.

\section{Materials and methods}

\section{Honeybee colonies}

Ten colonies of $A$. m. capensis were obtained from Heidelberg (Western Cape, South Africa), where the parasitic $A$. m. capensis population which invaded $A$. $m$. scutellata had its endemic distribution (Neumann et al. 2002). Four $A$. m. scutellata colonies heavily infested with social parasitic Cape honeybees were obtained from Graskop (Limpopo) and Heilbron (Free State, about $390 \mathrm{~km}$ apart) in the natural distribution area of $A . m$. scutellata in South Africa. Finally, a non-infested $A$. $m$. scutellata colony was carefully screened for signs of infestation (Härtel et al. 2006a) and obtained from a non-infested apiary in Pretoria (Gauteng). The colonies were placed on two apiaries in Grahamstown (Eastern Cape). After transport, all colonies were given 5 days to settle down in order to limit disturbance-induced absconding (Spiewok et al. 2006).

\section{The virulence and the transmission apiary}

The quantification of parasitic worker virulence was conducted with six queenright $A$. $m$. capensis colonies, which were placed at the "virulence" apiary. The experiment assessing the transmission capacity was conducted on a different "transmission" apiary (Fig. 1), which was spatially well separated from the virulence apiary $(>1 \mathrm{~km})$ to prevent drifting, dispersing and/or natural colony mergers (Neumann et al. 2001; Neumann and Moritz 2002) between the two experimental sites. The non-infested queenright $A$. $m$. scutellata 
colony served as a test ("sink") colony to quantify the horizontal transmission of parasitic workers from the "source" colonies, the four endemic A m capensis colonies (Western Cape) and the four heavily infested $A$. $m$. scutellata colonies. All source colonies were queenless to facilitate parasitic worker reproduction.

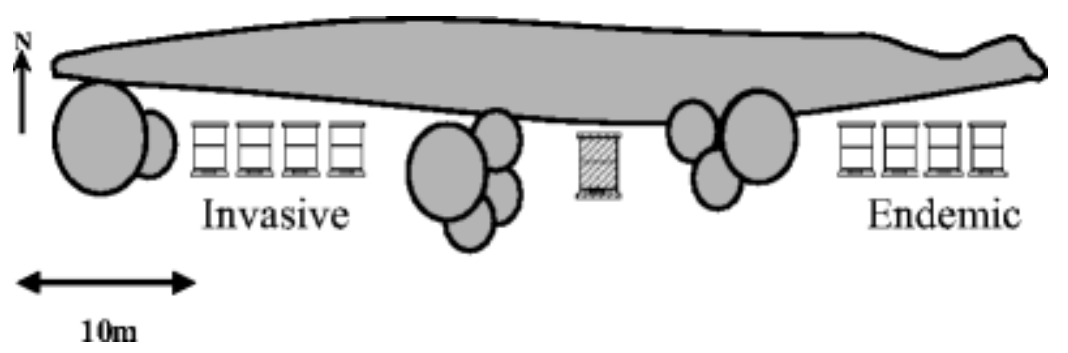

Fig. 1 Experimental design of the transmission apiary (white rectangles, source colonies with $A$. m. capensis laying workers from the invasive (Invasive) or endemic range (Endemic); shaded colony, A. m. scutellata sink colony; grey irregulars, vegetation)

\section{Within-host virulence}

In order to address within-host colony selection, it is not informative to test for symptoms at the colony level. Intracolonial selection is driven by differential individual fitness of the parasitic workers. We, therefore, determined the survival of parasitic worker-laid eggs as a measure of parasite virulence, which is primarily governed by the potential to evade worker policing (Martin et al. 2002). The removal of worker-laid eggs was investigated with standard methods (Ratnieks and Visscher 1989; Neumann et al. 2003; Pirk et al. 2003, 2004, 2007) for $A$. $m$. capensis queen- and worker-laid eggs from its endemic range (Heidelberg, Western Cape) and for A. m. capensis worker-laid eggs from the invasive population (Graskop and Heilbronn). Egg removal rates were determined by transferring queen-laid and worker-laid eggs from source colonies of each population into three queenright $A$. $m$. scutellata discriminator colonies. For each trial, ten diploid eggs from worker cells of all three types of source colonies were transferred into worker cells on a test comb. For each egg type, we had at least three replicate egg source colonies (queenlaid endemic, three colonies; worker-laid endemic, three colonies; worker-laid invasive, four colonies). The test combs were sandwiched between brood combs above a queen excluder and introduced into the three queenright discriminator colonies. All test frames were carefully screened for the occurrence of additional non-transferred eggs to exclude egg-laying by workers as a potential factor interfering with the evaluation of egg removal. The whole experiment was performed in the "virulence" apiary.

\section{Transmission}

The transmission capacity of the socially parasitic $A$. m. capensis workers was evaluated using a "common garden" experiment. The non-infested $A$. $m$. scutellata sink colony was separated by at least $10 \mathrm{~m}$ and dense vegetation from the source colonies (Fig. 1) to prevent accidental drifting (Neumann et al. 2001), which might mask active host finding of the social parasitic workers (dispersing; Neumann et al. 2001). The sink colony was carefully screened on a weekly basis for signs of infestation with parasitic $A$. m. capensis 
workers (Neumann and Hepburn 2002; Neumann and Moritz 2002; Härtel et al. 2006a). After 4 weeks, the sink colony showed all signs of the dwindling colony syndrome, including the loss of the host queen and the presence of worker-laid eggs (Neumann and Hepburn 2002). Three weeks later, sealed diploid-laying worker offspring (pupae) from all colonies (sink and source) at the transmission test apiary were sampled and stored in $75 \%$ ethanol for subsequent DNA genotyping to genetically identify the origin of the laying workers.

\section{Microsatellite DNA genotyping}

DNA was extracted from the sampled worker pupae (Walsh et al. 1991) and genotyped at four polymorphic microsatellite loci (A24, A28, A43, A107; Solignac et al. 2003).

Fragment sizes were scored using an ABI 310 automatic sequencer with the chemicals and protocols of the supplier (Applied Biosystems). Laying-worker matrilines were identified from the worker offspring genotypes using Mendelian rules and the Genotyper 20 software. Genotypes in the sink colony were compared with those present in the source colonies to determine horizontal laying-worker transmission.

\section{Results}

\section{Within-host virulence}

No additional non-transferred eggs appeared on the test frames during the experimental period, showing that laying-worker activity in the colonies did not interfere with the experiment. The mean numbers of surviving eggs were significantly different between worker-laid eggs from the invasive population and worker-laid and queen-laid eggs from the native Cape population (Table 1). Although, $A$. $m$. capensis worker-laid eggs from the invasive population showed higher removal rates than queen-laid eggs, it was three times less then that of endemic A. m. capensis worker-laid eggs (Table 1).

Table 1 Removal rates of $A$. $m$. capensis queen and worker-laid eggs

\begin{tabular}{|l|l|l|}
\hline Egg source & Population & Mean \pm SD \\
\hline Queen-laid & endemic $A$. . . capensis & $4.14 \pm 1.56^{*}$ \\
\hline Worker-laid & invasive $A$. m. capensis & $2.07 \pm 1.82^{*}$ \\
\cline { 2 - 3 } & endemic $A$. . . capensis & $0.71 \pm 1.44^{*}$ \\
\hline
\end{tabular}

The mean numbers $\pm \mathrm{SD}$ of remaining eggs in the test cells after $24 \mathrm{~h}$ are shown and were significantly different among the three tested groups (ANOVA, DF 2, $F=17.29, p<0.001$ ) *Significantly different at the $p<0.05$ level (Newman-Keuls test)

\section{Transmission}

A total number of 290 individuals were genotyped and assigned to laying-worker matrilines (Table 2). We detected 16 matrilines in the endemic source colonies, showing that laying-worker activity was abundant and many workers were unrelated and did not originate from the original mother queen of the source colonies. Because the genetic 
composition of the endemic laying workers was so heterogeneous, we could not definitely assign laying workers in the sink colony to one specific source colony based on offspring genotype. However, we could unambiguously identify laying workers from the invasive source colonies because all workers showed the typical genotype pattern with little recombination at locus A43 only.

Table 2 Genotypes of the A. m. capensis laying worker matrilines in the two source colonies (invasive and endemic) and in the A. m. scutellata sink colony

\begin{tabular}{|c|c|c|c|c|c|c|c|c|c|c|c|}
\hline \multirow{3}{*}{$\begin{array}{l}\text { Invasive source } A . m \text {. } \\
\text { capensis }\end{array}$} & \multirow{2}{*}{\begin{tabular}{|l|} 
Type \\
Invasive
\end{tabular}} & \multirow{2}{*}{\begin{tabular}{|l|} 
Matriline \\
1
\end{tabular}} & \multicolumn{2}{|c|}{ A107 } & \multicolumn{2}{|c|}{ A24 } & \multicolumn{2}{|l|}{ A28 } & \multicolumn{2}{|c|}{ A43 } & \multirow{2}{*}{$\frac{N}{67}$} \\
\hline & & & 176 & 181 & 90 & 94 & 131 & 131 & 121 & 142 & \\
\hline & Invasive & 2 & 176 & 181 & 90 & 94 & 131 & 131 & 121 & 121 & 3 \\
\hline Total & & 2 & & & & & & & & & 70 \\
\hline \multirow{16}{*}{$\begin{array}{l}\text { Endemic source } A . m \text {. } \\
\text { capensis }\end{array}$} & Endemic & 1 & 139 & 141 & 90 & 94 & 134 & 134 & 132 & 142 & 98 \\
\hline & Endemic & 2 & 139 & 167 & 90 & 94 & 128 & 134 & 120 & 142 & 56 \\
\hline & Endemic & 3 & 139 & 141 & 90 & 98 & 128 & 131 & 120 & 128 & 14 \\
\hline & Endemic & 4 & 159 & 189 & 90 & 98 & 124 & 131 & 124 & 128 & 12 \\
\hline & Endemic & 5 & nd $\mathrm{I}$ & nd & 92 & 94 & 128 & 128 & nd & nd & 2 \\
\hline & Endemic & 6 & nd & nd & 94 & 94 & 131 & 131 & 139 & 139 & 4 \\
\hline & Endemic & 7 & nd $\mathrm{I}$ & nd & 98 & 98 & 124 & 124 & 120 & 132 & 1 \\
\hline & Endemic & 8 & 147 & 159 & 90 & 98 & 124 & 124 & 132 & 132 & 2 \\
\hline & Endemic & 9 & 147 & 159 & 94 & 100 & 128 & 128 & 132 & 139 & 2 \\
\hline & Endemic & 10 & 147 & 174 & 90 & 94 & 128 & 128 & 128 & 142 & 3 \\
\hline & Endemic & 11 & 158 & 158 & 100 & 100 & 131 & 131 & 119 & 134 & 1 \\
\hline & Endemic & 12 & 158 & 164 & 100 & 100 & 128 & 128 & 121 & 121 & 1 \\
\hline & Endemic & 13 & 158 & 169 & 90 & 90 & 124 & 127 & nd & nd & 1 \\
\hline & Endemic & 14 & 166 & 166 & 90 & 94 & 131 & 131 & 120 & 120 & 3 \\
\hline & Endemic & 15 & 169 & 171 & 98 & 100 & 128 & 128 & nd & nd & 1 \\
\hline & Endemic & 16 & 189 & 189 & 98 & 98 & 124 & 124 & nd & nd & 1 \\
\hline Total & & 16 & & & & & & & & & 202 \\
\hline \multirow{8}{*}{$\begin{array}{l}\text { A. } m \text {. scutellata sink } \\
\text { colony }\end{array}$} & Endemic & 1 & 139 & 139 & 94 & 100 & 128 & 131 & 132 & 132 & 1 \\
\hline & Endemic & 2 & 139 & 139 & 96 & 100 & 128 & 134 & 132 & 132 & 1 \\
\hline & Endemic & 3 & 139 & 141 & 90 & 100 & 128 & 128 & 132 & 142 & 1 \\
\hline & Endemic & 4 & 139 & 171 & 90 & 100 & 124 & 124 & 126 & 132 & 1 \\
\hline & Endemic & 5 & 139 & 171 & 90 & 100 & 124 & 124 & 132 & 132 & 1 \\
\hline & Endemic & 6 & 139 & 171 & 90 & 100 & 128 & 128 & 128 & 142 & 3 \\
\hline & Endemic & 7 & 139 & 171 & 90 & 100 & 134 & 134 & 132 & 132 & 2 \\
\hline & Endemic & & 139 & 171 & 98 & 100 & 128 & 131 & 132 & 132 & 1 \\
\hline
\end{tabular}




\begin{tabular}{|l|l|l|l|l|l|l|l|l|l|l|l|l|l|||}
\hline & Type & Matriline & A107 & A24 & A28 & A43 & $N$ \\
\hline & Endemic & 9 & 141 & 141 & 90 & 100 & 128 & 134 & 126 & 132 & 1 \\
\hline & Endemic & 10 & 141 & 171 & 90 & 100 & 124 & 124 & 142 & 142 & 1 \\
\hline & Endemic & 11 & 167 & 171 & 90 & 100 & 124 & 128 & 126 & 142 & 1 \\
\hline & Endemic & 12 & 167 & 171 & 92 & 98 & 128 & 128 & 132 & 132 & 1 \\
\hline & Endemic & 13 & 167 & 171 & 92 & 98 & 134 & 134 & 142 & 142 & 1 \\
\hline & Endemic & 14 & 169 & 171 & 98 & 100 & 128 & 131 & 132 & 142 & 1 \\
\hline & Endemic & 15 & 169 & 171 & 100 & 100 & 128 & 131 & 132 & 132 & 1 \\
\hline
\end{tabular}

The allele lengths is given in base pairs for four loci $N d$ No amplification product; $N$ number of genotyped individuals In the sink colony, we identified $15 \mathrm{~A}$. $\mathrm{m}$. capensis laying-worker matrilines from more than one endemic source colony. Again, because of the high genetic variability of the laying workers, we could not assign genotypes to specific source endemic colonies. However, not a single worker from the invasive source colonies was detected in the sink colony, yielding a highly significant difference $\left(\chi^{2}=1413, D F=1, p<0.001\right)$ between the parasitic worker transmission of the endemic and the invasive $A$. $m$. capensis population. Furthermore, we found no offspring of the invasive type in the endemic source colonies nor vice versa (see Table 2). Thus, whereas only one parasitic lineage is found in source colonies from the invasive population, a high number of laying workers of various origins with high genetic variance is found in the endemic source colonies. Moreover, the invasive laying-worker type is completely lacking in the endemic source colonies although these were just placed a few meters away on the same apiary (Fig. 1) and had a higher virulence (Table 1).

\section{Discussion}

Our data show high within-host virulence but an undetectable small horizontal transmission rate of the invasive social parasitic $A$. $m$. capensis lineage, which caused the capensis calamity in $A$. $m$. scutellata populations. The weak transmission potential is further supported by the lack of the invasive parasitic clone in the endemic source colonies. Not a single offspring was detected in spite of a much higher abundance of invasive workers. In contrast, parasitic workers from the endemic $A$. $m$. capensis population showed threefold lower within-host virulence but an easily detectable transmission. Yet, in spite of the higher transmission potential, no endemic laying workers were detected in those source colonies with invasive parasitic workers. This fits well with the observation of the high within-host virulence of the invasive parasitic workers if the highly virulent type completely out-competed the less virulent type in all four colonies. All these characteristics are, therefore, contradicting the direct selection model, which predicts both a high virulence and a high transmission. The results are, however, perfectly in line with the predictions made by the short-sighted model of 
within-host evolution of virulence, suggesting that the winners of the within-host competition are poorer at transmission to new hosts (Bull 1994; Levin and Bull 1994). The short-sighted evolution model also agrees well with many field observations. On the one hand, the severe extent of the "capensis calamity" (Allsopp and Crewe 1993) strongly suggests a high virulence of the invasive clonal lineage (Neumann and Moritz 2002; Dietemann et al. 2006, 2007). On the other hand, the low infestation levels in wild A. $m$. scutellata host populations (particularly in nature conservation reserves) indicate that natural transmission of the invasive $A$. $m$. capensis lineage is low (Härtel et al. 2006a) and primarily facilitated by apicultural activities (Moritz 2002; Neumann and Hepburn 2002; Dietemann et al. 2006). Hence, apicultural practice resulting in a particular high density of colonies in apiaries may be the basis for the dramatic calamities in apiaries but not in the wild (Moritz 2002).

Thus, our results are clearly in line with epidemiological studies and the clinical symptoms of the capensis calamity all matching the predictions made by the short-sighted selection hypothesis for parasite virulence but neither for direct selection nor the coincidental selection of virulence hypothesis. Among the millions of parasitic workers introduced by man, apparently, the single most virulent parasitic worker out-competed all others (Neumann and Moritz 2002). This intracolonial competition is not only driven by egg survival but also through pheromonal competition, where workers with the strongest queen pheromone signal suppress reproduction of their competitors (Moritz et al. 1996; Simon et al. 2005; Dietemann et al. 2007). Because beekeepers facilitate the transmission of parasitic workers by tightly grouping colonies on apiaries and exchanging combs among colonies, the natural transmission capacity ought to be largely irrelevant for the spread of the invasive strain. Selection may exclusively act on the within-host level but will nevertheless have an impact at the population level because of artificial transmission by man.

Infested $A$. $m$. scutellata colonies rarely requeen from parasite offspring (Neumann and Moritz 2002). Moreover, the parasitic strain is unlikely to spread through sexual reproduction, because the highly virulent genotype depends on the thelytokous parthenogenesis of laying workers. Yet thelytoky is determined by homozygosity of the recessive $t h$-allele (Lattorff et al. 2007), and any sexual recombination with other alleles distorts this type of worker parthenogenesis. The specific highly virulent clonal parasitic genotype is maintained by the thelytokous parthenogenesis combined with a central fusion automixis and reduced recombination (Neumann and Moritz 2002). Thus, selection can operate on a highly virulent clonal genotype with a specific highly virulent combination of alleles at many loci rather than on individual virulence genes, which further enhances the potential for short-sighted selection.

The passage of the parasitic genotype through a sequence of multiple colonies, every time exposing them again to intracolonial selection for high virulence, is very similar to the serial passage experiments (Ebert 1998) where virulence of parasites can escalate in a few generations. The clonal structure of the invasive $A$. m. capensis social parasite population shows that the entire invasive population originated from a single laying $A . m$. capensis worker only in spite, or maybe even because, of multiple introductions (Allsopp 
1995). The base for the short-sighted selection mechanism is the large genotypic variability of multiple infections at the beginning of the process. The reduced dispersal capacity of this highly virulent clonal lineage is, to our knowledge, the first empirical evidence for the short-sighted selection hypothesis for parasite virulence (SchmidHempel 1998). It shows that the model is not confined to microparasite-host systems (Levin and Bull 1994) but that it can also be applied to other host-parasite systems. The generation time constraint is not essential if within-host genetic variance can be generated by other means (in our case, genetically variance through multiple infections). The prediction for the further fate of the capensis problem in South Africa will be that the virulence on the long run will again decrease because recombination, although rare, will eventually distort the high virulence genotype. The apicultural measures taken by actively selecting against colonies with parasitic bees (Härtel et al. 2006a) should enhance this process allowing for an optimistic assessment for the future development of South African apiculture.

\section{References}

Allsopp M (1992) The Capensis calamity. South Afr Bee J 64:52-57

Allsopp M (1993) Summarized overview of the Capensis problem. South Afr Bee J 65:127-136

Allsopp M (1995) The Capensis problem 1992-1995. In: Magnuson P (ed) Proceedings of the First International Electronic Conference on the Cape Bee problem in South Africa 05-30 June 1995. PPRI, Pretoria, pp 10-31

Allsopp M, Crewe RM (1993) The Cape honeybee as a Trojan horse rather than the hordes of Jenghiz Khan. Am Bee J 133:121-123

Baudry E, Kryger P, Allsopp M, Koeniger N, Vautrin D, Mougel F, Cornuet J-M, Solignac M (2004) Whole-genome scan in thelytokous-laying workers of the Cape honeybee (A. m. capensis): Central fusion, reduced recombination rates and centromere mapping using half tetrad analysis. Genetics 167:243-252

Beekman M, Calis JNM, Boot WJ (2000) Parasitic honeybees get royal treatment. Nature 404:723

Bull JJ (1994) Perspective - Virulence. Evolution 48:1423-1437

Dietemann V, Pflugfelder J, Härtel S, Neumann P, Crewe RM (2006) Social parasitism by honeybee workers (Apis mellifera capensis Esch.): evidence for pheromonal resistance to host queen's signals. Behav Ecol Sociobiol 60:785-793 
Dietemann V, Neumann P, Härtel S, Pirk CWW, Crewe RM (2007) Pheromonal dominance and the selection of a socially parasitic honeybee worker lineage (Apis mellifera capensis Esch.). J Evol Biol 20:997-1007

Ebert D (1998) Experimental evolution of parasites. Science 282:1432-1436

Härtel S, Neumann P, Kryger P, von der Heide C, Moltzer G-J, Crewe RM, van Praagh JP, Moritz RFA (2006a) Infestation levels of Apis mellifera scutellata swarms by socially parasitic Cape honeybee workers (Apis mellifera capensis Esch.). Apidologie 37:462-470

Härtel S, Neumann P, Raassen FS, Moritz RFA, Hepburn HR (2006b) Social parasitism by Cape honeybee workers in colonies of their own subspecies (Apis mellifera capensis Esch.). Insectes Soc 53:183-193

Hillesheim E, Koeniger N, Moritz RFA (1989) Colony performance in honeybees (Apis mellifera capensis Esch.) depends on the proportion of subordinate and dominant workers. Behav Ecol Sociobiol 24:291-296

Kryger P (2001) The pseudo-clone of Apis mellifera capensis — an obligate social parasite in honeybees. In: Proceedings of the XXXVII International Apicultural Congress, Durban, South Africa, p 33

Lattorff HMG, Moritz RFA, Crewe RM, Solignac M (2007) Control of reproductive dominance by the thelytoky gene in honeybees. Biol Lett 3:292-295

Levin BR (1996) The evolution and maintenance of virulence in microparasites. Emerg Infect Dis 2:93-102

Levin BR, Bull JJ (1994) Short-sighted evolution and the virulence of pathogenic microorganisms. Trends Microbiol 2:76-81

Martin SJ, Beekman M, Wossler TC, Ratnieks FLW (2002) Parasitic Cape honeybee workers, Apis mellifera capensis, evade policing. Nature 415:163-165

Moritz RFA (2002) Population dynamics of the Capebee phenomenon: the impact of parasitic laying worker clones in apiaries and natural populations. Apidologie 33:233244

Moritz RFA, Haberl M (1994) Lack of meiotic recombination in thelytokous parthenogenesis of laying workers of Apis mellifera capensis (the Cape honeybee). 
Heredity 73:98-102

Moritz RFA, Kryger P, Allsopp MH (1996) Competition for royalty in bees. Nature 384:522

Moritz RFA, Kryger P, Allsopp MH (1999) Lack of worker policing in the Cape honeybee (Apis mellifera capensis). Behaviour 136:1079-1092

Neumann P, Hepburn HR (2002) Behavioural basis for social parasitism of Cape honeybees (Apis mellifera capensis Esch.). Apidologie 33:165-192

Neumann P, Moritz RFA (2002) The Cape honeybee phenomenon: the evolution of a social parasite in real time. Behav Ecol Sociobiol 52:271-281

Neumann P, Radloff SE, Moritz RFA, Hepburn HR, Reece SL (2001) Social parasitism by honeybee workers (Apis mellifera capensis Esch): host finding and resistance of hybrid host colonies. Behav Ecol 12:419-428

Neumann P, Radloff SE, Hepburn HR (2002) Parasitic Cape bees in the northern regions of South Africa: source of the founder population. S Afr J Sci 98:404-406

Neumann P, Pirk CWW, Hepburn HR, Moritz RFA (2003) Spatial differences in worker policing facilitate social parasitism by Cape honeybee workers (Apis mellifera capensis Esch.) in queenright host colonies. Insectes Soc 50:109-113

Onions GW (1912) South African "fertile-worker bees". S Afr Agric J 1:720-728

Pirk CWW, Neumann P, Ratnieks FLW (2003) Cape honeybees, Apis mellifera capensis, police worker-laid eggs despite the absence of relatedness benefits. Behav Ecol 14:347352

Pirk CWW, Neumann P, Hepburn HR, Moritz RFA, Tautz J (2004) Egg viability and worker policing in honeybees. Proc Natl Acad Sci U S A 101:8649-8651

Pirk CWW, Neumann P, Hepburn HR (2007) Nestmate recognition for eggs in the honeybee (Apis mellifera L). Behav Ecol Sociobiol 61:1685-1693

Ratnieks FLW, Visscher PK (1989) Worker policing in the honey bee. Nature 342:796797

Schmid-Hempel P (1998) Parasites in social insects. Princeton University Press, 
Princeton, NJ

Simon U, Moritz RFA, Crewe RM (2005) Reproductive dominance among honeybee workers in experimental groups of Apis mellifera capensis. Apidologie 36:413-419

Solignac M, Vautrin V, Loiseau A, Mougel F, Baudry E, Estoup A, Garnery L, Haberl M, Cornuet J-M (2003) Five hundred and fifty microsatellite markers for the study of the honeybee (Apis mellifera L) genome. Mol Ecol Notes 3:307-311

Spiewok S, Neumann P, Hepburn HR (2006) Preparation for disturbance-induced absconding of Cape honeybee colonies (Apis mellifera capensis Esch). Insectes Soc 53:27-31

Walsh PS, Metzger DA, Higuchi R (1991) Chelex 100 as a medium for simple extraction of DNA for PCR-based typing from forensic material. Biotechniques 10:506-51 